\title{
siRNA directed against c-Myc inhibits proliferation and downregulates human telomerase reverse transcriptase in human colon cancer Colo 320 cells
}

\author{
Huang $\mathrm{Hao}^{\dagger 1,2}$, Yu Nancai ${ }^{1}$, Fu Lei ${ }^{\dagger 1}$, Wei Xiong 3 , Su Wen ${ }^{1}$, Huang Guofur ${ }^{1}$, \\ Wu yanxia ${ }^{1}$, Huang Hanju ${ }^{2}$, Liu Qian ${ }^{1}$ and Xiao Hong*1
}

Address: ${ }^{1}$ Center of Experimental Medicine, Wuhan No.1 Hospital, Wuhan, 430022, PR China, ${ }^{2}$ Department of Pathogentic Biology, Tongji Medical College, Huazhong University of Science and Technology, Wuhan, 430030, PR China and ${ }^{3}$ Brain Research Center, University of British Columbia, Vancouver, BC, Canada

Email: Huang Hao - hao4@163.com; Yu Nancai - yunancai2000@yahoo.com.cn; Fu Lei - wuhanhuanghao10@yahoo.com.cn; Wei Xiong - weixiong0718@yahoo.com; Su Wen - wuhanhuanghao10@yahoo.com.cn; Huang Guofu - hgfmkp@yahoo.com.cn; Wu yanxia - wuhanhuanghao10@yahoo.com.cn; Huang Hanju - juguangying@yahoo.com.cn; Liu Qian - LiuQian9097@yahoo.com.cn; Xiao Hong* - wuhanhuanghao10@yahoo.com.cn

* Corresponding author †Equal contributors

Published: 12 August 2008

Journal of Experimental \& Clinical Cancer Research 2008, 27:27 doi:10.1 186/1756-9966-27-27
Received: 22 May 2008

Accepted: 12 August 2008

This article is available from: http://www.jeccr.com/content/27/I/27

(c) 2008 Hao et al; licensee BioMed Central Ltd.

This is an Open Access article distributed under the terms of the Creative Commons Attribution License (http://creativecommons.org/licenses/by/2.0), which permits unrestricted use, distribution, and reproduction in any medium, provided the original work is properly cited.

\begin{abstract}
The c-Myc and human telomerase reverse transcriptase gene (hTERT) gene are frequently deregulated and overexpressed in malignancy. hTERT activity is induced by c-Myc and strategies designed to inhibit c-Myc expression in cancer cells may have considerable therapeutic value. We designed and used a short hairpin RNA to inhibit c-Myc expression in Colo 320 cells and validated its effect on cell proliferation. In this study, four c-Myc-shRNA expression vectors were constructed and introduced into Colo 320 cells. The effects of c-Myc silencing on tumor cell growth was assessed by soft agar assay and DNA synthesis experiments. The expressions of c-Myc and hTERT were also assessed by real-time reverse transcription-polymerase chain reaction and Western blot analysis. Upon transient transfection with plasmid encoding shRNA, it was found that expression of c-Myc and hTERT decreased in shRNA-transfected cells. The downregulation of cMyc and hTERT inhibited cell growth, shortened telomere lengths, and suppressed telomerase activity. In conclusion, our findings demonstrate that shRNA of c-Myc can inhibit the DNA replication in Colo 320 cells effectively and reduce telomere length and telomerase activity, therefore, it could be used as a new potential anticancer tool for therapy of human colon cancer.
\end{abstract}

\section{Background}

Telomerase is a ribonucleoprotein enzyme that synthesizes telomeres, i.e., DNA repeats that cap and protect the ends of chromosomes[1]. The core of the mammalian telomerase holoenzyme is the catalytic subunit, telomerase reverse transcriptase, which adds hexameric DNA repeats (TTAGGG) that correspond to the telomerase RNA com- ponent known as TERC[2,3]. Telomerase activation has been regarded as a crucial step in cellular carcinogenesis, and it is one of the most common molecular markers in a broad spectrum of malignancies [4]. It has been reported that telomerase activity is significantly high in about $80 \%$ of cancers and correlates well with the degree of malignancy[5]. Some studies have shown that hTERT gene 
expression is more specific and sensitive than telomerase activity in the diagnosis of malignant neoplasms, as the hTERT gene is overexpressed in about $90 \%$ of malignant tumors [6]. The control of c-Myc gene expression is a complex process and occurs at various steps of transcription, such as initiation, elongation, and attenuation, as well as during the post-transcriptional stages[7,8].

The protein product of the c-Myc protooncogene plays a vital role in the process of cellular growth and differentiation[9]. Deregulation of c-Myc expression has been detected in many cancers and is believed to be an important step in carcinogenesis [10]. In addition, c-Myc has also been implicated in the regulation of telomerase through its ability to induce the transcriptional activation of hTERT[11]. RNA interference (RNAi) has been described.

Recently, a post-transcriptional gene silencing pathway mediated by double-stranded RNA (dsRNA), also called RNA interference (RNAi) has been described[12,13]. RNAi is a natural mechanism of defence, which protects cells against exogenous dsRNA, such as viral or deriving from transposones[14]. When a dsRNA enters the cytoplasm, RNAse III Dicer can process it to produce several small interfering RNAs (siRNAs), 21-23 nucleotide long RNA molecules with 2 nucleotide long 3 'overhangs. Small interfering RNAs may get incorporated into the RNA induced silencing complex (RISC), which identifies and silences complementary RNAs generally through a cleavage mechanism. In the last few years, it has been demonstrated that siRNAs represent an efficient tool to modulate the expression of a large number of cancer-related genes[15].

In the present study, we selectively downregulated c-Myc expression in human colon cancer Colo 320 cells with siRNA delivered via a plasmid-based polymerase III promoter system. This approach allowed us to explore a possible role for $\mathrm{c}-\mathrm{Myc}$ in regulating telomerase activity.

\section{Methods}

Short-interfering RNA design

shRNA directed against c-Myc mRNA were selected using the computer program (web site http:// www.ambion.com/techlib/misc/siRNA finder.html),

and it was verified, by BLAST search, that there was no homology with another human gene. shRNA \#1-4 sequences directed against c-Myc mRNA were selected according to Blast search score and GC content (40-60\%). The shRNA expression cassette contained 19 nucleotide of the target sequence followed by the loop sequence (TTCAAGACG), reverse complement to the 19 nucleotide, stop codon for U6 promoter and BamHI site (c-Myc -1: 5'CTATGACCTCGACTACGACTTCAAGACCGTCCTAGTC-
GAGGTCATAG-3'; c-Myc -2: 5'-AAATTCGAGCTGCTGCCC TTCAAGACG GGGCAGCAGCTCGAATTTC-3'; cMyс -3: 5'GCCCCCAAGC TAGTTATC TTCAAGACG GATAACTACCTTGGGGGCC-3'; c-Myc -4: 5'CCACAGCATACATCCTGT TTCAAGACG ACAGGATGTATGCTGTGGC-3'). The shRNA cassettes and their complementary strands were synthesized (Wuhan Genesil Biotechnology, Wuhan, China).

\section{Cell culture and transfection}

The colon cancer cell line Colo 320 was obtained from China Center for TypeCulture Collection (GDC298). The cells were grown in RPMI-1640 medium (GIBCO, Invitrogen, Carlsbad, CA) supplemented with $10 \%$ fetal bovine serum (Gibco BRL), 50 units/ml penicillin, and $50 \mu \mathrm{g} / \mathrm{ml}$ streptomycin. The Colo 320 cells were maintained in a humidified $37^{\circ} \mathrm{C}$ incubator with $5 \% \mathrm{CO}_{2}$, fed every 3 days with complete medium, and subcultured when confluence was reached. The cells were routinely passaged every 1 or 2 days. For transfection, $2 \times 10^{5}$ cells were seeded into each well of a six well tissue culture plate (Costar). The next day (when the cells were 70-80\% confluent), the culture medium was aspirated and the cell monolayer was washed with pre-warmed sterile phosphate-buffered saline (PBS). Cells were transfected with the pGensil-c-Myc -1, -2, 3, and -4 harboring green pEGFP-C1 green fluorescence protein reporter gene by using Lipofectamine 2000 reagent (Invitrogen, Carlsbad, $\mathrm{CA}$ ) in accordance with the manufacturer's protocol. Cells were continuously cultured until harvest for analysis.

\section{Cell counts}

Colo 320 cells were trypsinized on the indicated days and counted with a hemocytometer. We quantify cell proliferation by comparing the number of cells counted before and after transfection. Colo 320 Approximately 200 cells were evaluated in each sample using the hemocytometer. cell viability was assessed by trypan blue exclusion (Sigma-Aldrich China Inc, Shanghai, China).

\section{DNA synthesis}

Colo 320 cells were treated with $1 \mathrm{mCi}$ of $3 \mathrm{H}$-thymidine per milliliter (Amersham Biosciences, Piscataway, NJ) for the last $6 \mathrm{~h}$ of day 3 after shRNA treatment. Cells were then rinsed twice with PBS, ice-cold 5\% trichloroacetic acid, and $80 \%$ ethanol; the incorporated radioactivity of cell lysates was measured in a liquid scintillation counter.

\section{Soft agar colony assay}

Two days after transfection, Colo 320 cells (300 cells per well) transfected with indicated plasmids were mixed with tissue culture medium containing $0.7 \%$ agar to result in a final agar concentration of $0.35 \%$. Then $1 \mathrm{ml}$ sample of this cell suspension was immediately plated in six-well plates coated with $0.6 \%$ agar in tissue culture medium (2 
$\mathrm{ml}$ per well) and cultured at $37^{\circ} \mathrm{C}$ with $5 \% \mathrm{CO}_{2}$. After 2 weeks, the top layer of the culture was stained with $0.2 \%$ piodonitrotetrazolium violet (Sigma). The culture was analyzed in triplicate, and colonies larger than $100 \mu \mathrm{m}$ in diameter were counted.

\section{Quantification of c-Myc and hTERT mRNA}

For the sqRT-PCR analysis, total RNA was isolated using Trizol reagent (Sigma) and reversely transcribed using random hexamers with Superscript II (Invitrogen). For cMyc and hTERT detection, CDNA was mixed with the PCR reaction mixture and each $\mathrm{C}-\mathrm{Myc}$ and hTERT-specific primer (LT5 and LT6). The PCR cycle number was set up to permit the distinction between mRNA expression profiles among the samples. PCR products were visualized on $1.2 \%$ agarose gel. Actin was used as an internal control, and positive and negative controls were always included. PCR reagents were from the Master Taq kit (Eppendorf).

\section{Telomere length measurement}

Determination of telomere length was performed by Southern analysis of telomere restriction fragment (TRF) length. Genomic DNA was isolated from transfected cells using DNA isolation kit (Qiagen, Valencia, CA, USA) and quantified by UV spectrophotometry. Two micrograms of DNA were digested with restriction endonucleases RsaI and HinfI. The DNA digests were electrophoresed through $0.8 \%$ agarose and transferred to nylon membranes by capillary transfer in $20 \times$ SSC as described.

After UV crosslinking $(1200 \mu \mathrm{J})$, the membranes were hybridized with a 3'-digoxigenin oligonucleotide probe with the sequence (CCCTAA) $3 '$ '. After washing to remove unbound probe, an alkaline phosphatase-conjugated anti-digoxigenin antibody (Roche Applied Science, Indianapolis, IN, USA) was used for immunodetection of bound probe, followed by CDP Star chemiluminescence substrate (Roche Applied Science). Blots were exposed to X-ray film for 10-60 s. Mean TRF length and percentage photo-stimulated luminescence were determined from densitometric analysis of digital images of exposed films as described. Measurements of TRF length were performed in duplicate for each membrane.

\section{Detection of telomerase activity}

The telomerase activity was measured using a PCR-TRAP ELISA kit (Roche, USA) according to the manufacturer's description with some modifications. For the TRAP reaction, $2 \mu \mathrm{g}$ total RNA was added to $25 \mu$ of reaction mixture with the appropriate amount of sterile water to create a final volume of $50 \mu \mathrm{l}$. Hybridization and the ELISA reaction were carried out following the manufacturer's instructions.

\section{Western blotting}

Transfected cells were washed twice with PBS and suspended in IPH lysis buffer (50 mM Tris (pH 8.0), $150 \mathrm{mM}$ $\mathrm{NaCl}, 5 \mathrm{mM}$ EDTA, 0.5\% NP40, $100 \mathrm{mM}$ phenylmethyl sulfonyl fluoride leupeptin $1 \mathrm{mg} / \mathrm{mL}$, aprotinin $1 \mathrm{mg} / \mathrm{mL}$, and $1 \mathrm{M}$ dithiothreitol). Cells were extracted at $4^{\circ} \mathrm{C}$ for 30 min. After centrifugation at $12,000 \mathrm{rpm}$ for $20 \mathrm{~min}$, the supernatant was subject to electrophoresis on $10 \%$ sodium dodecyl sulfate-polyacrylamide gel (SDS-PAGE), and transferred to a polyvinylidene difluoride (PVDF) membrane. The membrane was allowed to react with anti$\beta$-actin polyclonal, anti-c-Myc and hTERT antibody (Santa Cruz Biotechnology). Specific antibodies were detected with a chemiluminescence kit (Sigma Life Science) according to the supplier's manual. Chemiluminescence was detected by exposure to X-ray film.

\section{Statistical analysis}

All data in the text and figures is presented as means \pm standard deviation (means \pm SD). Statistical analysis was performed using Student's t-test.

\section{Results}

\section{Effect of the c-Myc small interfering RNA on cell growth}

As the first step, transfection efficiency of the plasmid encoding shRNA for c-Myc in Colo 320 cells was examined by coexpressing pEGFP green fluorescence protein. When the cells were examined under a fluorescence microscope $24 \mathrm{~h}$ after transfection, more than $75-85 \%$ of them was transfected (Figure 1A).

We then tested whether RNAi-mediated c-Myc could influence the ability of Colo 320 cells to form colonies in soft agar. Colo 320 cells were transfected with pGensil-cMyc or empty vector. At 48 hours after transfection, the cells were placed into medium with soft agar, and colonies were counted after 2 weeks. RNAi directed against cMyc resulted in a significant decrease (about 65\%) in colony formation in Colo 320 cells (Figure 1B-1,2,3). These results showed that suppression of $\mathrm{c}-\mathrm{Myc}$ by RNAi could decrease the ability of colon cancer cells to form colonies in soft agar.

Since four constructs gave similar results, we describe the results with pGenesil - c-Myc - 1 in the subsequent experiments. We also evaluated the effect of c-Myc-specific shRNA on Colo 320 cell proliferation. Cell proliferation was measured by counting the number of viable cells using trypan blue staining. Transfected c-Myc-shRNA (Figure $1 \mathrm{C}-1$ ) resulted in a marked inhibition of cell proliferation over this 2-day period and the shRNAs induced antiproliferative effect was dose dependent. Cell growth was not influenced significantly by treatment with controlshRNA and vector. The statistical analysis shows that Colo 320 cell proliferation was affected by silencing of c-Myc. 

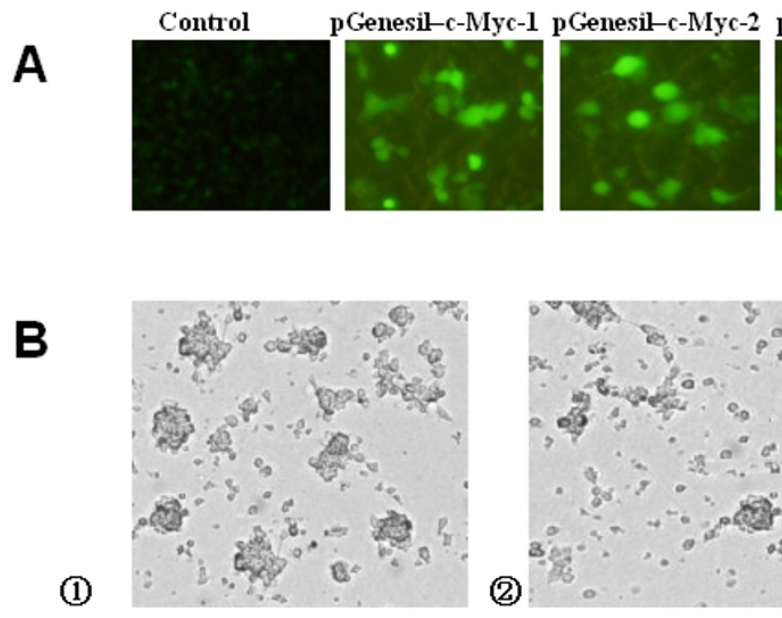

(2)
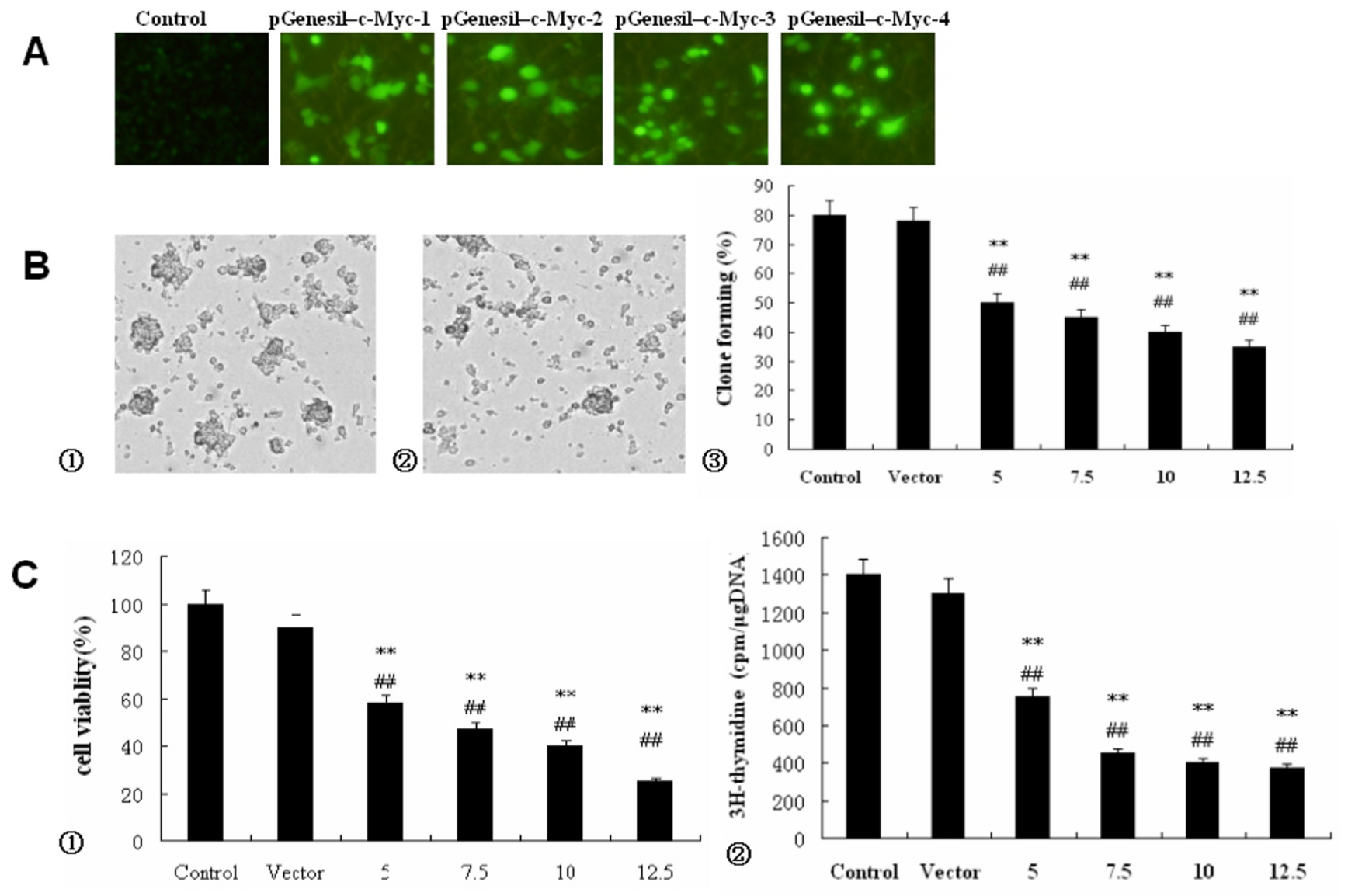

\section{Figure I}

Effect of shRNA on proliferation of Colo 320 cells. A. Plasmid pGenesil-c-Myc- I,-2, -3 , and -4 with pEGFP encoding green fluorescence protein were transfected to the cells. B. c-Myc-depletion inhibits colony formation of Colo 320 cells. B-I) Control Colo 320 cells. B-2) Colo 320 cells treated with pGenesil-c-Myc-I for 24 h B-3) The percentage of colonies of pGenesil-c-Myc-I treated cells standardized against the corresponding control. C. Cells were treated with increasing concentrations of shRNA for $48 \mathrm{~h}$. C-I)Cell viability was determined by cell counts. Results are expressed as the percentage of viable cells in the treatment groups with respect to that in the corresponding control. C-2) Cell proliferation following shRNA treatments for $48 \mathrm{~h}$ was quantified by $3 \mathrm{H}$-thymidine incorporation studies. All data were obtained from three independent experiments. Error bars represent means \pm SEM. Significantly different from the corresponding control $(* * P<0.01$, vs control. \#\#P $<0.0$, vs vector).

This is further confirmed with DNA synthesis assay using $3 \mathrm{H}$-thymidine. In Figure 1C-2, the cell control and vector showed the maximum counts of $(3 \mathrm{H})$ thymidine (around 1400 and $1350 \mathrm{cpm} / \mu \mathrm{gDNA}$ ) when compared to the treatment groups. In addition, the anti-proliferative effect was dose dependent and maximum inhibition was achieved with $12.5 \mu \mathrm{M}$ shRNA.

\section{Down-regulation of c-Myc and hTERT by expression of ShRNA}

Compared with untreated cells, c-Myc and hTERT mRNA abundance was significantly decreased in cells incubated with $5,7.5,10$, or $12.5 \mu \mathrm{M}$ shRNA for $48 \mathrm{~h}(\mathrm{P}<0.01)$.
Control and empty vector group markedly expressed cMyc mRNA (Figure 2A) $(\mathrm{P}<0.01)$.

As Western blot analysis indicated, the shRNA was able to reduce c-Myc and hTERT protein expression. As indicated in (Figure 2B), shRNA treatment inhibited the protein expression levels of c-Myc genes, representative downstream targets for c-Myc and hTERT protein in Colo 320 cells $(\mathrm{P}<0.01)$. Transfection with shRNA at different concentrations $(0,5,7.5,10,12.5)$ resulted in the significant attenuation of expression of c-Myc and hTERT protein (P $<0.01)$. In contrast, $\beta$-actin protein expression was not affected by shRNA. These data indicated that vector-based 


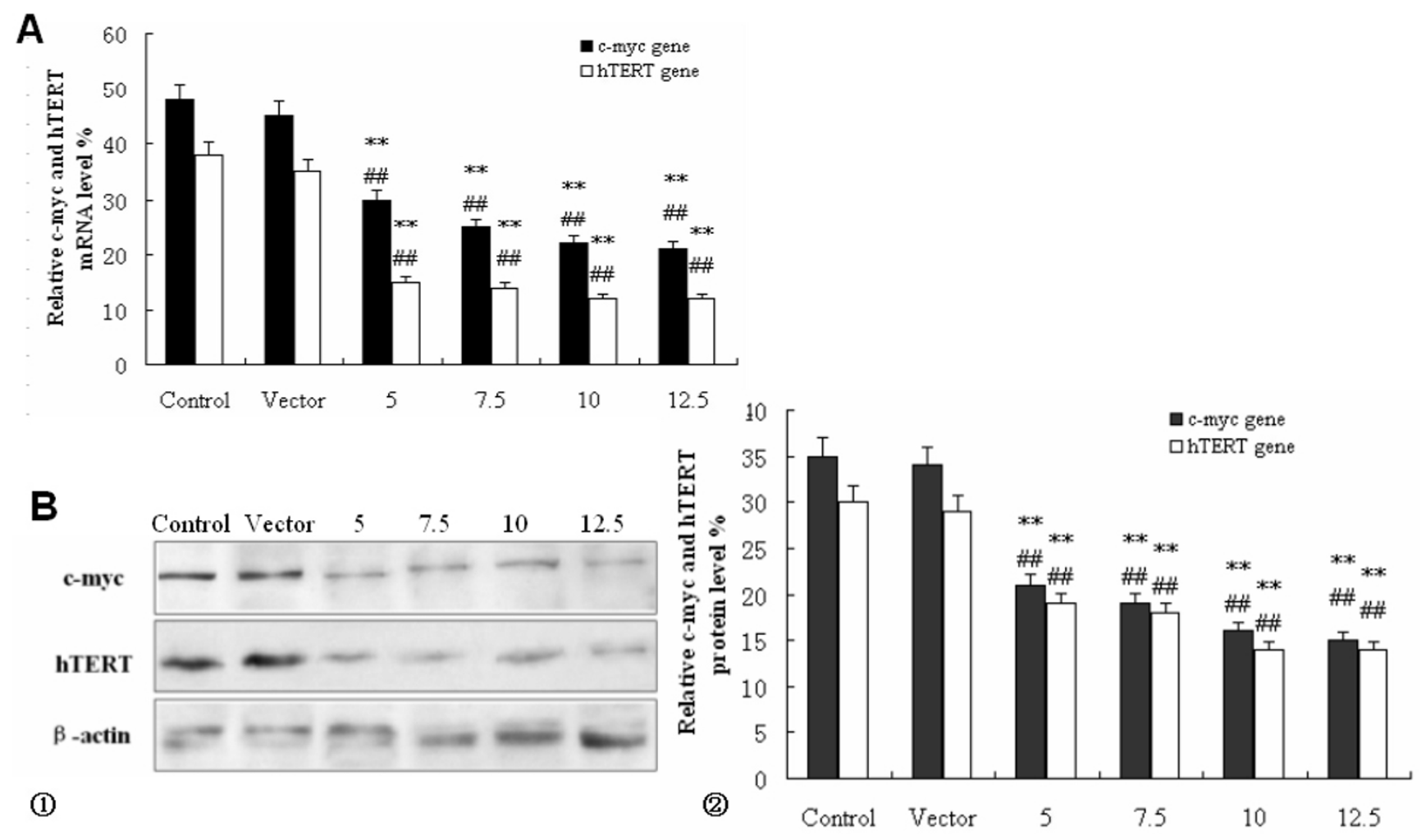

\section{Figure 2}

Effect of shRNA on expression of c-Myc and hTERT gene in Colo 320 cells. A. c-Myc and hTERT mRNA expression of Colo 320 cells was detected by RT-PCR with different treatments. The cells were subjected to no treatment (control), pGenesil-vector group, 5, 7.5, 10, $12.5 \mu \mathrm{M}$ shRNA for 48 h. B. c-Myc protein and hTERT expression of Colo 320 cells was detected by Western blotting with different treatments. Typical Western blot results for c-Myc and hTERT protein. Protein expression of c-Myc in Colo 320 cells was quantified by densitometric analysis. All data were obtained from three independent experiments. Error bars represent means \pm SEM. Significantly different from the corresponding control (**P < $0.0 \mathrm{I}$, vs control. \#P $<0.0$ I, vs vector).

RNAi could effectively suppress c-Myc and hTERT overexpression.

\section{Effects of shRNA on telomere length and telomerase activity}

We evaluated the effect of shRNA on telomerase activity. Our data suggested that shRNA could down-regulate telomerase activity in shRNA-transfected groups. Telomerase activity were shown in Figure 3A. It revealed that shRNAtransfected groups had lower telomerase activity than the control groups. shRNA at a variety of concentrations resulted in significant reduction of telomerase activity.

TRF length then was determined using pulse gel electrophoresis followed by Southern blot hybridization with telomere-specific probes. Average telomere length is shown in Figure 3B-1. Telomere length in shRNA-transfected groups telomeres was shorter than the one in the control groups. Transfection of shRNA resulted in signifi- cant increment of mean telomere length (Figure 3B-2, $\mathrm{P}<$ 0.05).

\section{Discussion}

Some researchers have shown that c-Myc act as a transcription factor, which binds with E-box sites (CACGTG) of a gene's cis-element to regulate other gene transcription, such as hTERT gene[16]. C-Myc forms a dimer with Max, then binds to the specific E-box site sequence 5'-CACGTG3 ' to transactivate target genes[17]. In contrast, c-Myc may also form a dimer with mad1 at the same binding site to suppress the transcription of target genes[18].

It has been shown that telomerase is highly related with malignant neoplasms [19]. When cells change from the normal growth status to abnormal growth status, there is persistent telomerase activity[20]. Previous studies showed that hTERT expression is related to many factors; in particular, that hTERT transcript regulation is affected 

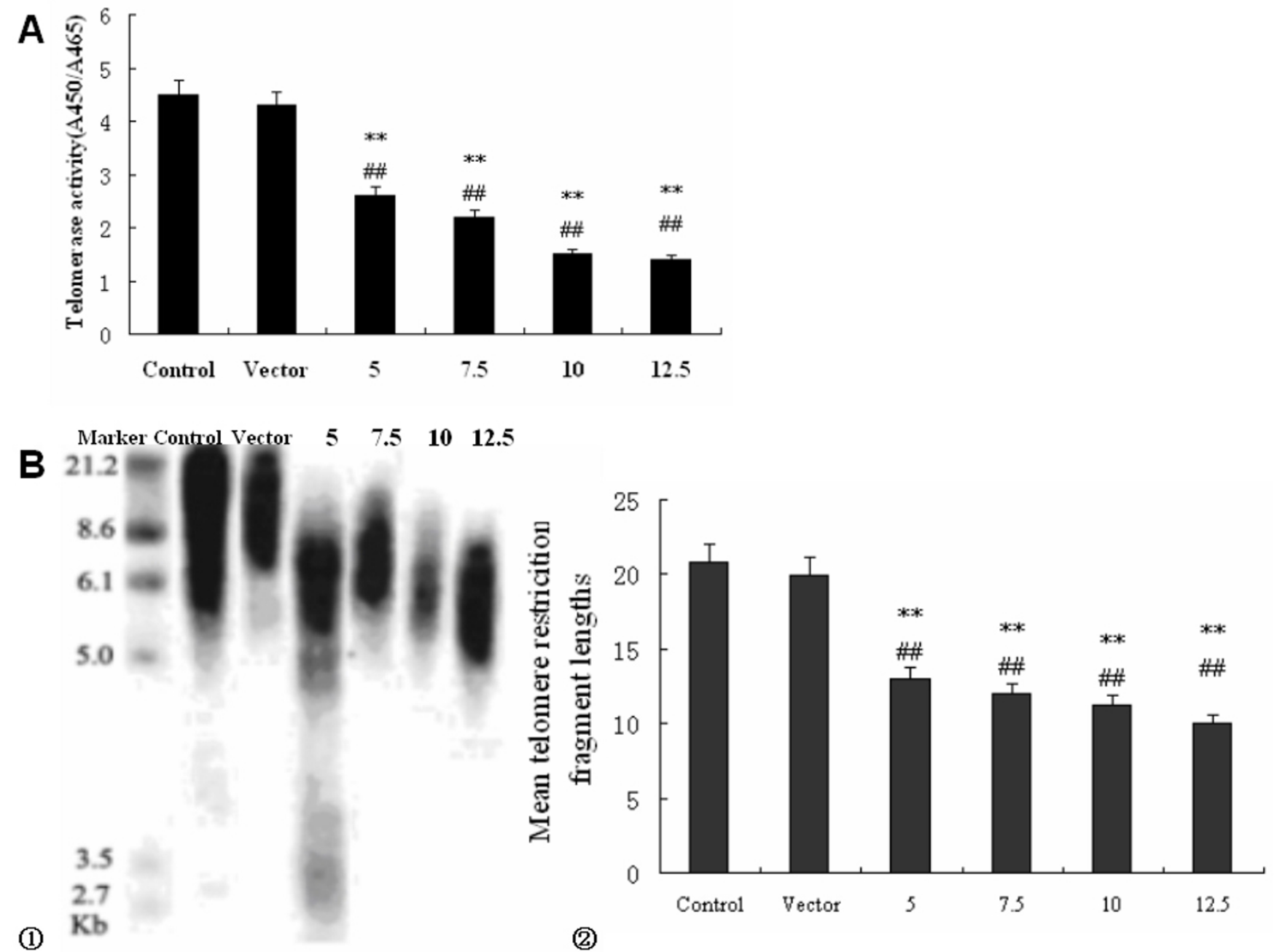

\section{Figure 3}

Effects of shRNA on telomere length and telomerase activity in Colo 320 cells. A. Representative the concentration-course analysis of telomerase activity, each groups cells were mixed with I ml TBA solution for preparation of protein extract and I $\mu \mathrm{g}$ protein was subjected to TRAP assay. After hybridization and ELISA procedure, the absorbance of the samples at $450 \mathrm{~nm}$ was measured. The cells were subjected to no treatment (control), pGenesil-vector group, 5, 7.5, I0, I2.5 $\mu \mathrm{M}$ shRNA for $48 \mathrm{~h}$. B. Mean telomere restriction fragment length was detected by RT-PCR with different treatments by Southern analysis as described under Materials and methods. Typical Southern blot results for telomere restriction fragments. Locations of the base pair markers on the DNA ladder are indicated along the left side. Significant difference was observed between the mean telomere lengths of the control and shRNA-transfected groups cells. All data were obtained from three independent experiments. Error bars represent means \pm SEM. Significantly different from the corresponding control $(* * \mathrm{P}<0.0 \mathrm{I}$, vs control. \#\# < 0.0 I, vs vector).

by different transcription factors such as c-Myc[21,22]. Others report that activation or inhibition of c-Myc expression can change hTERT promoter activity[23,24]. The up-regulation, of c-Myc can trans-activate hTERT promoter and consequently activates telomerase. Xu et al suggest that c-Myc can activate hTERT transcription in a dosedependent manner in leukemia cells. Several studies have shown that downregulating c-Myc activity induces tumor shrinkage[25].
In the present study, we used vector-based shRNA technique and constructed the recombinant plasmid expressing c-Myc-shRNA to transfect Colo 320 cells. Our results demonstrated that a transient reduction of c-Myc protein level by RNAi could significantly inhibit the growth rate of Colo 320 cells and its ability to form colonies in soft agar. Based on the results of western blotting, we also confirmed that the specific c-Myc-shRNA designed and used in this study successfully reduce the expression of the c- 
Myc and hTERT. We also found the We also found the attenuation of c-Myc and hTERT protein expression was dose-dependent.

Telomerase activity is strongly associated with telomere length maintenance. In the present study, we analyzed telomere length and telomerase activity in shRNA-transfected Colo 320 cells. Fig. 3 shows that the shRNAtransfected group had a shorter telomere length and lower telomerase activity than control group. Therefore, shRNA can significantly reduce telomere length and telomerase activity in siRNA-transfected Colo 320 cells.

In summary, we have identified the c-Myc shRNA that specifically inhibits activated c-Myc and suppresses cell proliferation. The c-Myc shRNA is able to block c-Myc DNAbinding activity and reduces the levels of c-Myc mRNA. Meanwhile, c-Myc shRNA can significantly reduce telomere length and telomerase activity in shRNA-transfected Colo 320 cells. Targeting c-Myc activation with RNAi may hold therapeutic promise for colon cancer with c-Myc and telomerase activation.

\section{Acknowledgements}

This work is supported by Foundation for Medicine Scientific Research Project of Wuhan from Wuhan Ministry of Health, PR China.

\section{References}

I. Morin GB: The human telomere terminal transferase enzyme is ribonucleoprotein that synthesizes TTAGGG repeats. Cell 1989, 59:521-529.

2. Counter CM, Meyerson M, Eaton EN, Weinberg RA: The catalytic subunit of yeast telomerase. Proc Natl Acad Sci USA 1997, 94:9202-9207.

3. Mitchell JR, Wood E, Collins K: A telomerase component is defective in the human disease dyskeratosis congenita. Nature 1999, 402:55I-555.

4. Wright WE, Piatyszek MA, Rainey WE, Byrd W, Shay JW: Telomerase activity in human germline and embryonic tissues and cells. Dev Genet 1996, 18:173-179.

5. Janknecht R: On the road to immortality: hTERT upregulation in cancer cells. FEBS Lett 2004, 564:9-13.

6. Kim NW, Piatyszek MA, Prowse KR, Harley CB, West MD, Ho PL, Coviello GM, Wright WE, Weinrich SL, Shay JW: Specific association of human telomerase activity with immortal cells and cancer. Science 1994, 266:2011-2015.

7. Pelengaris S, Khan M, Evan G: c-Myc: more than just a matter of life and death. Nat Rev Cancer 2002, 2(a):764-76.

8. Nilsson JA, Cleveland JL: Myc pathways provoking cell suicide and cancer. Oncogene 2003, 22:9007-9021.

9. Miliani de Marval PL, Macias E, Rounbehler R, Sicinski P, Kiyokawa $\mathrm{H}$, Johnson DG, Conti C], Rodriguez-Puebla ML: Lack of cyclindependent kinase 4 inhibits c-myc tumorigenic activities in epithelial tissues. Mol Cell Biol 2004, 24:7538-7547.

10. Murphy DJ, Swigart LB, Israel MA, Evan GI: Id2 is dispensable for Myc-induced epidermal neoplasia. Mol Cell Biol 2004, 24:2083-2090.

II. Gunes C, Lichtsteiner S, Vasserot AP, Englert C: Expression of the hTERT gene is regulated at the level of transcriptional initiation and repressed by MadI. Cancer Res 2000, 60:2II6-2I 21 .

12. Fire A, Xu S, Montgomery MK: Potent and specific genetic interference by double-stranded RNA in Caenorhabditis elegans. Nature 1998, 391:806-II.

13. Hannon G], Rossi J]: Unlocking the potential of the human genome with RNA interference. Nature 2004, 43 I:37I-78.
14. Yu JY, Deruiter SL, Turner DL: RNA interference by expression of short-interfering RNAs and hairpin RNAs in mammalian cells. Proc Natl Acad Sci USA 2002, 99:6047-52.

15. Dasgupta R, Perrimon N: Using RNAi to catch Drosophila genes in a web of interactions: insights into cancer research. Oncogene 2004, 23:8359-65.

16. Casillas MA, Brotherton SL, Andrews LG, Ruppert JM, Tollefsbol TO: Induction of endogenous telomerase (hTERT) by c-Myc in WI-38 fibroblasts transformed with specific genetic elements. Gene 2003, 316:57-65.

17. James $L$, Eisenman RN: Myc and Mad bHLHZ domains possess identical DNA-binding specificities but only partially overlapping functions in vivo. Proc Natl Acad Sci USA 2002, 99:10429-10434.

18. D'Cruz CM, Gunther EJ, Boxer RB: c-MYC induces mammary tumorigenesis by means of a preferredpathway involving spontaneous Kras2 mutations. Nat Med 200I, 7:235-239.

19. Poole JC, Andrews LG, Tollefsbol TO: Activity, function, and gene regulation of the catalytic subunit of telomerase (hTERT). Gene 200I, 269:I-I2.

20. Meeker AK, de Marzo AM: Recent advances in telomere biology. Implications for human cancer. Curr Opin Oncol 2004, 16:32-38.

21. Cerni C: Telomeres, telomerase, and myc. An update. Mutat Res 2000, 462:31-47.

22. Gunes C, Lichtsteiner S, Vasserot AP, Englert C: Expression of the hTERT gene is regulated at the level of transcriptional initiation and repressed by Mad I. Cancer Res 2000, 60:2II6-2I 2 I.

23. Nikiforov MA, Popov N, Kotenko I, Henriksson M, Cole MD: The Mad and Myc basic domains are functionally equivalent. J Biol Chem 2003, 278: I 1094-II099.

24. Cerezo A, Kalthoff H, Schuermann M, Schafer B, Boukamp P: Dual regulation of telomerase activity through $c-M y c-d e p e n d e n t$ inhibition and alternative splicing of hTERT. J Cell Sci 2002, II 5: $1305-1312$

25. Xu D, Popov N, Hou M, Wang Q, Bjorkholm M, Gruber A, Menkel $A R$ : Switch from Myc/Max to MadI/Max binding and decrease in histone acetylation at the telomerase reverse transcriptase promoter during differentiation of $\mathrm{HL} 60$ cells. Proc Natl Acad Sci USA 200I, 98:3826-383I.

Publish with Biomed Central and every scientist can read your work free of charge

"BioMed Central will be the most significant development for disseminating the results of biomedical research in our lifetime. "

Sir Paul Nurse, Cancer Research UK

Your research papers will be:

- available free of charge to the entire biomedical community

- peer reviewed and published immediately upon acceptance

- cited in PubMed and archived on PubMed Central

- yours - you keep the copyright 